UNIVERSIDADE DE SÃO PAULO

FACULDADE DE ECONOMIA, ADMINISTRAÇÃO E CONTABILIDADE DEPARTAMENTO DE ADMINISTRAÇÃO PROGRAMA DE PÓS-GRADUAÇÃO EM ADMINISTRAÇÃ̃o

\title{
APLICAÇÃO DO CAPM PARA A DETERMINAÇÃO DO CUSTO DE CAPITAL PRÓPRIO NO BRASIL
}

Nathália Würzler Bellizia

Prof. Dr. José Roberto Ferreira Savoia 
Prof $^{\mathrm{a}}$ Dra. Suely Vilela

Reitora da Universidade de São Paulo

Prof. Dr. Carlos Roberto Azzoni

Diretor da Faculdade de Economia, Administração e Contabilidade

Prof. Isak Kruglianskas

Chefe do Departamento de Administração

Prof. Dr. Lindolfo Galvão de Albuquerque Coordenador do Programa de Pós-Graduação em Administração 


\section{NATHÁLIA WÜRZLER BELLIZIA}

\section{APLICAÇÃO DO CAPM PARA A DETERMINAÇÃO DO CUSTO DE CAPITAL PRÓPRIO NO BRASIL}

Dissertação apresentada ao Departamento de Administração da Faculdade de Economia

Administração e Contabilidade da Universidade de São Paulo como requisito para a obtenção de título de Mestre em Administração

Orientador: Prof. Dr. José Roberto Savoia 


\section{FICHA CATALOGRÁFICA}

\section{Elaborada pela Seção de Processamento Técnico do SBD/FEA/USP}

\section{Bellizia, Nathália Wurzler}

Aplicação do CAPM para a determinação do custo de capital próprio no Brasil / Nathália Wurzler Bellizia. -- São Paulo, 2009.

$120 \mathrm{p}$.

Dissertação (Mestrado) - Universidade de São Paulo, 2009

Bibliografia.

1. Administração financeira 2. Finanças das empresas 3. Mercado de capitais I. Universidade de São Paulo. Faculdade de Economia, Administração e Contabilidade II. Título.

CDD -658.15 